\title{
Spatial Spillover Effects of Renewable Energy on Carbon Emissions in Less-Developed Areas of China
}

\section{Jun Bai}

China University of Geosciences

Shixiang LI ( $\square$ lishixiang@cug.edu.cn )

China University of Geosciences https://orcid.org/0000-0002-1858-6295

Qiying Kang

China University of Geosciences

\section{Nan Wang}

China University of Geosciences

\section{Kailu Guo}

China University of Geosciences

\section{Jinfeng Wang}

China University of Geosciences

Jinhua Cheng

China University of Geosciences

\section{Research Article}

Keywords: renewable energy, carbon emissions, spatial spillover, SDM, direct and indirect effects, lessdeveloped areas

Posted Date: August 20th, 2021

DOI: https://doi.org/10.21203/rs.3.rs-774949/v1

License: (a) (i) This work is licensed under a Creative Commons Attribution 4.0 International License. Read Full License

Version of Record: A version of this preprint was published at Environmental Science and Pollution Research on October 27th, 2021. See the published version at https://doi.org/10.1007/s11356-02117053-w. 
1 Spatial Spillover Effects of Renewable Energy on Carbon Emissions

2

3

4

5

\section{in Less-developed Areas of China}

Jun Bai ${ }^{1}$, Shixiang Li ${ }^{2 *}$, Qiying Kang ${ }^{1}$, Nan Wang ${ }^{1}$, Kailu Guo ${ }^{1,3}$, Jinfeng Wang ${ }^{1}$, Jinhua Cheng ${ }^{2}$

${ }^{1}$ School of Public Administration, China University of Geosciences, Lumo Road 388, Wuhan 430074, China

${ }^{2}$ Mineral Resources Strategy and Policy Research Center, China University of Geosciences, Lumo Road 388, Wuhan 430074, China

${ }^{3}$ School of Management, Taiyuan Normal University, Jinzhong, 030619, China

\section{${ }^{*}$ Corresponding author}

E-mail: lishixiang@cug.edu.cn (Shixiang Li)

\section{Abstract}

The purpose of this paper is to determine the spatial spillover effects of renewable energy on carbon emissions in China's less-developed areas. However, few studies have considered this issue from the perspective of less-developed areas. Based on panel data of 21 provinces in China from 2000 to 2017, this paper investigates the spatial spillover effects of renewable energy on carbon emissions using Moran's I and Spatial Durbin Model (SDM). The results suggest that, first, Moran's I ranges from 0.378 to 0.519 , Moran scatter plot presents that provinces are located in the high-high (HH) and lowlow (LL) quadrants, indicating provincial carbon emissions in the study area have a significant spatial correlation and agglomeration. Second, under the three matrices, the direct effect coefficients of renewable energy are $-0.2522,-0.2639$ and -0.2601 , this shows that renewable energy is beneficial to local carbon emissions reduction. In contrast, the indirect effect coefficients of renewable energy are 0.0605, 0.1012 and 0.1125 , which means higher renewable energy consumption in a single area is conducive to the improvement of carbon emissions to neighbouring areas. Third, urbanization, industrialization, physical capital and other variables have different 
28 impacts on local and nearby carbon emissions. This study provides empirical evidence 29 to achieve carbon emission reduction targets by government policymakers.

30 Keywords: renewable energy, carbon emissions, spatial spillover, SDM, direct and 31 indirect effects, less-developed areas 


\section{Introduction}

Against the background of carbon peaking and carbon neutralization, carbon emissions reduction has gradually become a broad consensus and conscious action around the world (Cheng and Yao 2021). On the one hand, the frequent occurrence of extreme climatic events caused by carbon emissions has posed a great threat to the sustainability of natural ecosystems (Sugiawan et al. 2019), resulting in, the deterioration of ecosystems, the extinction of bio-species, smog, acid rain, and the greenhouse effect, among others. On the other hand, climate warming caused by the wanton emission of carbon dioxide has serious adverse impacts on global development (Withey 2019; Yang et al. 2020). Currently, there is fierce competition in ecological protection, resource utilization and industrial development around the world, the imbalance of international development has intensified. In the face of these crises (Ajani 2013; Qin et al. 2020), more countries are seeking to protect the Earth's fragile ecological system by cooperating within the framework of the Intergovernmental Panel on Climate Change (IPCC). In particular, it should be noted that the IPCC has issued five special reports on global climate change, calling on countries around the world to strengthen cooperation and technological innovation to address the risks and challenges of the global carbon crisis ( $\mathrm{Li}$ et al. 2020). Many responsible countries have signed constructive cooperation agreements, such as the United Nations Framework Convention on Climate of 1992, the Kyoto Protocol of 1997, the Bali Roadmap of 2007, the Copenhagen Accord of 2012, and the Paris Agreement of 2015 (Lau et al. 2012; Gao et al. 2017; Vrontisi et al. 2020).

As a member and signatory of the above-mentioned agreements, China attaches great importance to greenhouse gas (GHG) reduction and promised to reduce carbon emissions in 2035 by $40 \%-50 \%$ compared to that of 2005 (Zhang et al. 2020). It is generally known that China is the world's largest developing country and emerging economy. In 2020, China's gross domestic product (GDP) accounted for more than 17\% of global GDP. Meanwhile, as reported by the National Bureau of Statistics of China 
(NBSC), total energy consumption reached 4.98 billion tonnes of standard coal, ranking China first in the world for many years (NBSC 2021). Among these forms of energy, coal consumption accounts for $56.8 \%$, and natural gas, hydropower, nuclear power, wind power together make up only $24.3 \%$. Extensive use of fossil energy leads to rapid increases of carbon dioxide. According to the British Petroleum (BP) Statistical Review of World Energy 2020, China's total carbon dioxide emissions reached 9825.8 million tonnes of oil equivalent (Mtoe), approximately $28.8 \%$ of total global emissions (BP 2020). The increase of carbon dioxide in China has brought about an unimaginable crisis in the development of human societies (Ouyang and Lin 2014; Jiang et al. 2019), such as drought, flood and other disasters. Therefore, China is also facing great pressure in carbon emissions reduction, the nation has inevitably moved to develop renewable energy sources (RES) to reduce carbon dioxide output.

Renewable energy is an ideal substitute for fossil energy. Up to now, China's renewable energy reserves account for 36\% of the world's total (Li et al. 2020), and renewable energy investment exceeded US\$760 billion from 2010 to 2020, almost onethird of the global amount (Mi and Liao 2020; Yang et al. 2020). As a result, China has become the most important driving force for global renewable energy, but its problems cannot be ignored (Zhao and Luo 2017). The major concerns are as follows. First, China's economic and ecological benefits of renewable energy have not been fully exerted (Shuai et al. 2020), especially because the suppression of carbon dioxide emissions is not yet significant, and the value and potential of the country's renewable resources need to be further developed. Second, the unbalanced development of renewable energy in China is prominent, and progress in the less-developed central and western regions is typical (Yu et al. 2019). Therefore, it is of great practical value to attach importance to the development of renewable energy in China's less-developed areas, change the inequality of regional renewable energy development, protect the ecological environment and economic development.

The rest of the paper is organized as follows: a brief literature review of renewable energy theories and methods is offered in Section 2. Section 3 describes the study area, 
variables, data sources, and models. Empirical results are presented in Section 4. Sections 5 provides a discussion. Section 6 presents the study's conclusions, and important policy implications.

\section{Literature Review}

Excessive carbon emissions in the environment is considered as a contributor to the global GHG (López et al. 2013). Reducing carbon emissions and seeking alternative clean energy have become the concerted action of global nations (Liu et al. 2019). In terms of carbon emissions, renewable energy is cleaner than traditional fossil fuels (Sarkodie et al. 2020). Therefore, renewable energy and carbon emissions have received a growing concern by scholars and policy markers in the field of energy, economy and environment. Previous literature about renewable energy and carbon emissions can be divided into three main categories.

The first category studies the relationship between renewable energy and carbon emissions. Based on the policies of renewable energy and carbon emissions, many of the prior published articles used the propensity score matching and difference in differences (PSM-DID) model to study the relationship between renewable energy and carbon emissions. For example, due to the demands of economic growth, abundant energy resources and low environmental standards (Al-mulali and Tang 2013), some scholars believe that even in developed countries, there is not long-term positive relationship between renewable energy and carbon emissions (Baek 2015), especially in undeveloped economies where the sustainable development of carbon emissions cannot be realized easily (Caviglia-Harris et al. 2009; Yao et al. 2019). However, with the technological advancement and social development, more and more scholars have put forward different viewpoints. Their results found that for every $1 \%$ increase in renewable energy consumption, carbon dioxide emissions are reduced by $0.1641 \%$ to 0.2601\%. (Dong et al. 2017). Meanwhile, when per capita GDP reached US\$2,938, renewable energy had a significant negative effect on carbon emissions (Sinha and Shahbaz 2018; Cheng et al. 2019). It is not difficult to find that there is a stable positive 
relationship between renewable energy and carbon emission reduction.

The second category analyzes the carbon emissions reduction effects of renewable energy on investment growth, trade service and other aspects. Ordinary least squares (OLS) regression and generalized method of moments (GMM) are often used to estimate the sample statistics for studying renewable energy and carbon emissions. For instance, using dynamic OLS and GMM, the exsting research shows that developed countries can transfer carbon emissions through foreign direct investment and international trade services (You and Solomon 2015), and it created a serious carbon crisis to developing or undeveloped nations (Khan et al. 2020), this is extremely unequal. Furthermore, as the same methods described above, according to a great deal of field surveies conducted by Berk et al. (2018), Hu et al. (2018) and Adam and Nsiah (2019), whether in dvevloped or undeveloped countries, the contribution of renewable energy to the primary energy consumption of the states were found to have strong convergence. Therefore, new environmental protection policies are necessary to curb carbon emissions, such as innovative renewable energy products (Hansen 2012), environmental regulation (Guo and Chen 2018), trade upgrade (Bermudez-Edo 2018), research and development (R\&D) subsidies (Wu et al. 2020).

The third category refers to the spatial effect of renewable energy. At present, it is extensively applied in the fields of the environment and the economy, among others (Acheampong et al. 2019). For example, using spatial model optimization, relevant studies proposed a method for estimating and comparing the potential supply of RES and their potential capacity factor (Vettorato et al. 2011; Park and Hur 2018). Furthermore, based on the improved spatial analysis model, researchers found that the spatial spillover effect of renewable energy on economic growth exists in European Union (EU) countries. Specifically, they showed that every $1 \%$ increase in the renewable energy consumption of one country corresponds to an increase in economic growth of up to $0.054 \%$ in the GDP of neighbouring countries (Shahnazi and Shahnazi 2020; Chica-Olmo et al. 2020). Similarly, China's development practice showed that although fossil energy has a positive effect on economic growth, it has a negative spatial 
spillover effect on the increase of carbon emissions in neighbouring regions ( $\mathrm{Li}$ and $\mathrm{Li}$ 2020). Therefore, it is urgent to develop renewable energy to gradually replace fossil fuels (Su and Yu 2020).

So far, an abundance of interesting research has been conducted on renewable energy consumption, environment, and economy, especially in terms of theoretical innovations and model applications. To be sure, the above-quoted literature lays a solid foundation for this paper to study the spatial spillover effects of renewable energy on carbon emissions. However, some important questions have been ignored in the literature. First, existing research mainly focuses on economically developed or undeveloped countries, while less attention is paid to less-developed areas, especially the less-developed parts of China's central and western regions. Second, scholars use traditional static models, such as OLS and GMM, to study the internal relationship between renewable energy and carbon emissions, but few use spatial dynamic measurement models, so there is an urgent need to make a difference in this field.

\section{Methodology}

\subsection{Study Area}

There are 21 provinces explored in this paper, including Anhui, Chongqing, Gansu, Guangxi, Guizhou, Hainan, Hebei, Heilongjiang, Henan, Hubei, Hunan, Jiangxi, Jilin, Inner Mongolia, Ningxia, Qinghai, Shanxi, Shannxi, Sichuan, Yunnan, and Guizhou (Fig. 1). Tibet is not included in this paper because some data is missing.

According to the China Statistical Yearbook 2020 (NBSC 2020), the per capita disposable income of the 21 provinces was between 19139 and 30555 Chinese Yuan (CNY), lower than that of Beijing, Shanghai, Tianjin, Shandong, Zhejiang, Jiangsu, Guangdong, Fujian and Liaoning (The average per capita disposable income of the above nine provinces is $45439 \mathrm{CNY}$ ), it also lower than the overall average per capita disposable income of $30733 \mathrm{CNY}$. In addition, all 21 provinces are located in the central and western regions of China, the contradiction between energy consumption, economic growth and environmental protection is prominent. There is no doubt that 
175

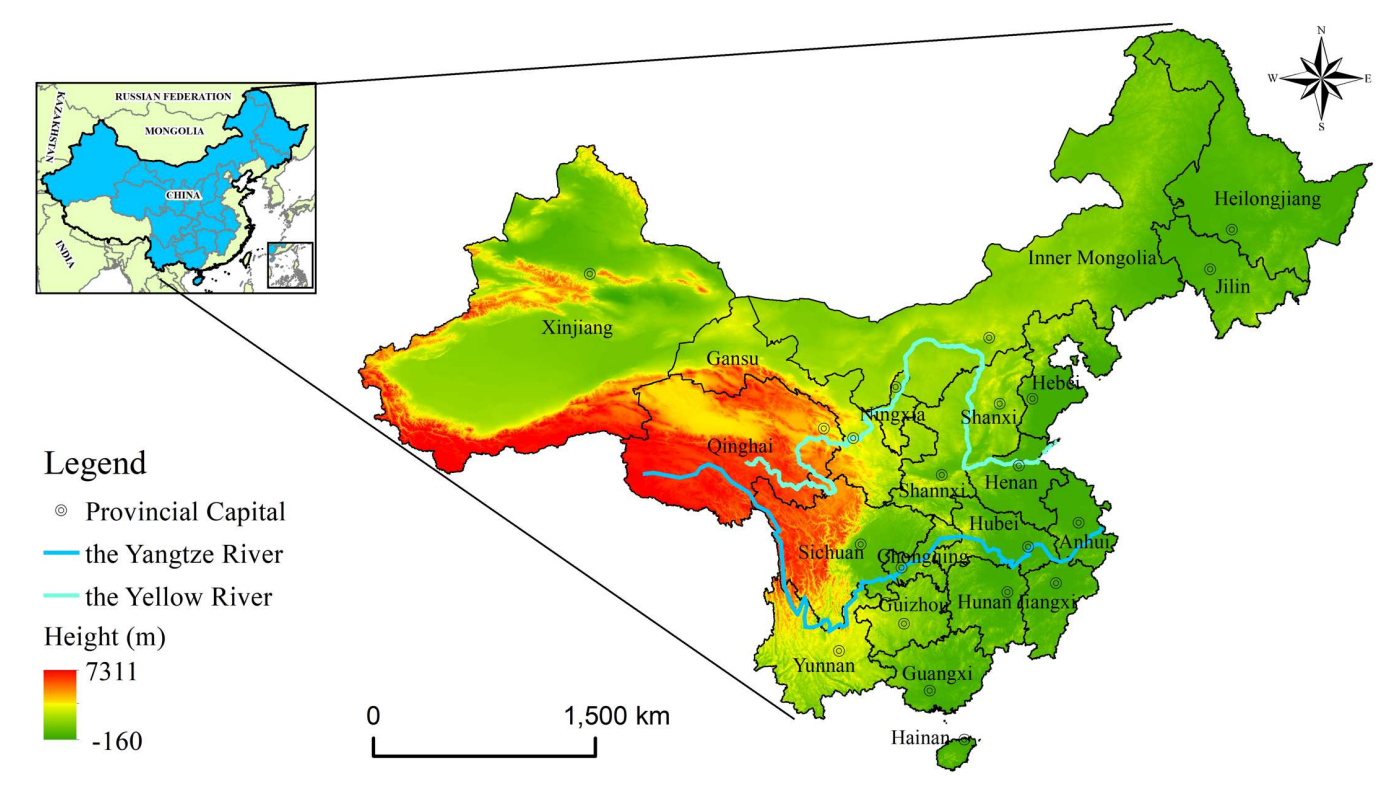

Fig. 1. Study area.

\subsection{Variables and Data}

\subsubsection{Definition of Variables}

The variables used in this study are divided into explained variable, explanatory variables, and control variables, as follows. First, with the growing negative effects of fossil energy consumption on the global ecological environment, the carbon emissions puzzle is one that increasingly affects the world's economic health and sustainable development, and includes hidden dangers. It has become a hot topic in the field of environmental economy. Therefore, this study uses carbon emissions $(c b)$ as the explained variable in the next research.

Because the Chinese central government has not released annual carbon emissions data for each province, the paper refers to the IPCC study 2006 and to Chen (2011). The carbon emissions of China's less-developed areas can be estimated using Equation 1:

$$
C B_{\mathrm{t}}=\sum_{i=1}^{3} E_{i, t} * N C V_{i} * C E F_{i} * C O F_{i} * \frac{44}{12}
$$


where $\boldsymbol{C B}_{\boldsymbol{t}}$ is the estimated carbon emissions, $\boldsymbol{i}$ represents three primary energy forms, $\boldsymbol{E}$ measures energy consumption, $\boldsymbol{N C} \boldsymbol{V}$ is the net calorific value (calculated by the IPCC), $\boldsymbol{C E F}$ and $\boldsymbol{C O F}$ are the carbon emissions coefficient and carbon oxidation coefficient, respectively, and 44/12 represents the mass fraction of carbon in carbon dioxide. The corresponding estimated coefficients are shown in Table 1, and they generally have been accepted by scholars in other countries.

Table 1. Carbon emissions estimation coefficients of three primary energy sources.

\begin{tabular}{ccccc}
\hline Energy & $\begin{array}{c}\mathbf{N C V} \\
\left(\mathbf{k J} / \mathbf{k g}, \mathbf{~ k J} / \mathbf{m}^{\mathbf{3}}\right)\end{array}$ & $\begin{array}{c}\boldsymbol{C E F}(\mathbf{I P C C}, \mathbf{2 0 0 6}) \\
\mathbf{k g} / \mathbf{m i l l i o n ~} \mathbf{k J}\end{array}$ & $\boldsymbol{C O F}$ & $\begin{array}{c}\text { Converted to } \\
\text { standard coal (tce/t) }\end{array}$ \\
\hline Coal & 20,908 & 26 & 0.99 & 0.7143 \\
Crude oil & 41,816 & 20 & 1 & 1.4286 \\
Natural gas & 38,931 & 15.3 & 1 & 1.3300 \\
\hline
\end{tabular}

Data sources: The China Energy Statistical Yearbook 2019 and the IPCC (2006).

Explanatory variables used in the analysis include renewable energy consumption (nec) and per capita GDP (pgdp) (Sun and Huang 2020).

- Renewable energy consumption refers to the proportion of renewable energy power generated in the whole year.

- Per capita GDP is the ratio of GDP to total population.

Carbon emissions may affected by some factors, such as urbanization (ur), industrialization (ir), human capital $(h c)$, physical capital $(p c)$, technological innovation (ty) (Erdogan 2021). In this paper, these factors are the control variables.

- Urbanization is the proportion of the urban resident population out of the total population.

- Industrialization is the ratio of industrial added value to GDP.

- Technological innovation is R\&D expenditures as a proportion of GDP.

- Human capital is obtained by a reasonable estimation of the labour value of employees according to their level of education, using Equation 2:

$$
H C=h_{1} * 2+h_{2} * 6+h_{3} * 9+h_{4} * 12+h_{5} * 16
$$

where $\boldsymbol{h}_{1} \ldots \boldsymbol{h}_{5}$ are dummy variables representing illiteracy, elementary school, junior 
middle school, senior middle school, and institutions of higher education or above.

Based on the research of Zhang et al. (2004), this study estimates the physical capital of each province with the perpetual inventory method shown in Equation 3:

$$
K_{i t}=K_{i t-1} *\left(1-\delta_{i t}\right)+I_{i t}
$$

where $\boldsymbol{K}_{\boldsymbol{i t}}$ is the total physical capital of province $\boldsymbol{i}$ in year $\boldsymbol{t}, \boldsymbol{I}_{\boldsymbol{i t}}$ is the investment of province $\boldsymbol{i}$ in year $\boldsymbol{t}$, and $\boldsymbol{\delta}$ is the depreciation rate $(\delta=9.6 \%)$.

\subsubsection{Description of the Data}

The data used in this paper are from 2000 to 2017 (2018-2021 data have not been released). The data on carbon emissions and renewable energy consumption are from the China Energy Statistical Yearbook and the Statistical Review of World Energy. Per capita GDP, urbanization rate, industrial rate, human capital, physical capital, and technological innovation are derived from the China Statistical Yearbook and the NBSC. The results of the statistical analysis are shown in Table 2.

Table 2. Statistical descriptions of variables.

\begin{tabular}{cccccc}
\hline Variables & Maximum & Minimum & Mean & Standard deviation & Observations \\
\hline$c b$ & 86387.08 & 538.53 & 23315.72 & 17658.81 & 378 \\
$p g d p$ & 22757.90 & 2661.56 & 72064.00 & 15623.17 & 378 \\
$n e c$ & 69.27 & 0.03 & 13.18 & 15.51 & 378 \\
$u r$ & 64.08 & 23.2 & 43.21 & 9.40 & 378 \\
$i r$ & 61.50 & 19.76 & 46.00 & 7.38 & 378 \\
$h c$ & 67223.38 & 1600.88 & 20233.02 & 13553.77 & 378 \\
$p c$ & 1657983.00 & 739.00 & 124258.20 & 227080.70 & 378 \\
$t y$ & 7006253.00 & 8306.00 & 1047010.00 & 1347033.00 & 378 \\
\hline
\end{tabular}

\subsection{Methods}

\subsubsection{Spatial Weight Matrix}

Provincial carbon emissions are affected by factors such as geographic location 
and economic differences, and they produce spatial interaction effects. Therefore, the spatial weight matrix plays a vital role in the reliability and stability of the estimated results. Based on existing research, in order to compare the impact of renewable energy on carbon emissions under different spatial weight matrices (Cole et al. 2013; Jia et al. 2021), the matrix of this paper includes adjacency matrix $\left(\boldsymbol{W}_{\boldsymbol{l}}\right)$, economic distance matrix $\left(\boldsymbol{W}_{2}\right)$, and gravity model matrix $\left(\boldsymbol{W}_{3}\right)$.

Whether the spatial location is adjacent is the basis for judging the adjacency matrix. If the two provinces are adjacent, $\boldsymbol{W}_{\boldsymbol{l}}=1$; if they are unadjacent, $\boldsymbol{W}_{\boldsymbol{l}}=0$ (Equation 4).

$$
W_{1}= \begin{cases}1, & i=j \\ 0, & i \neq j\end{cases}
$$

This paper uses the reciprocal of the difference in GDP as the weight to measure the degree of adjacency between provinces. The larger the GDP gap between the two provinces, the smaller the weight assignment; otherwise, the smaller the GDP gap, the greater the weight assignment (Equation 5).

$$
W_{2}=\left\{\begin{array}{l}
\frac{1}{\overline{G D P_{i}}-\overline{G D P_{j}}}, i \neq j \\
0, i=j
\end{array}\right.
$$

Gravity model matrix is also called economic-geographic matrix. Both geographical and economic factors are considered in the calculation of this matrix. Compared with the adjacency matrix and the economic matrix, the gravity matrix can measure the degree of influence of regional interaction more accurately. As shown in

\section{Equation 6:}

$$
W_{3}=W_{d} * \operatorname{diag}\left(\frac{\overline{G_{1}}}{\bar{G}}, \frac{\overline{G_{2}}}{\bar{G}}, \cdots \frac{\overline{G_{\mathrm{n}}}}{\bar{G}}\right)
$$

where $\boldsymbol{W}_{\boldsymbol{d}}$ represents the latitude and longitude distance between the provincial capitals of each province; $\bar{G}$ indicates the average per capita GDP; $\overline{G_{1}}, \overline{G_{2}} \ldots \overline{G_{n}}$ represent 
the average real per capita GDP of each province in one year; and $\operatorname{diag}\left(\frac{\overline{G_{1}}}{\bar{G}}, \frac{\overline{G_{2}}}{\bar{G}}, \cdots \frac{\overline{G_{n}}}{\bar{G}}\right)$ is the diagonal matrix.

\subsubsection{SDM}

As Tobler (1970) says, everything is related to everything else, but things that are in close proximity are more closely related to each other. Especially in research on environment and resource issues, it is not sufficient to conduct a single linear study based on the time dimension. Rather, scholars must also consider the spatial factor in the model, using the correction function of the spatial weight matrix to construct a complex econometric model. However, SDM can solve this problem very well because it considers not only the spatial correlation among the variables in a certain area, but also the spatial correlation that may be affected by the variables of neighbouring areas (LeSage and Pace 2009). The estimated results of the model are more in line with reality. Therefore, this paper integrates the theoretical knowledge of econometrics, $\mathrm{PPH}$, and others through the method of SDM by using spatial panel data from 2000 to 2017 to study the spatial spillover effects of renewable energy development on carbon emissions in China's less-developed areas from two dimensions: time and space. This is captured by Equation 7:

$$
C B=\beta_{0}+\rho \sum W C+\beta_{1} W p g d p+\beta_{2} W n e c+\theta_{1} u r+\theta_{2} i r+\theta_{3} h c+\theta_{4} p c+\theta_{5} t y+\varepsilon
$$

where $\boldsymbol{C B}$ is the carbon emissions (explanatory variable), $\boldsymbol{\rho}$ represents the spatial regression coefficient, $\boldsymbol{W}$ signifies the spatial weight matrix, $\boldsymbol{\beta}$ and $\boldsymbol{\theta}$ are regression coefficients, and $\boldsymbol{e}_{\boldsymbol{i}}$ is the random error term.

\section{Empirical Results}

\subsection{Moran's I}

Moran's I was used to test the spatial autocorrelation of the 21 less-developed areas of central and western China, and can lay a solid theoretical and methodological 
280 foundation for further study of the spatial spillover effects of renewable energy 281 development on carbon emissions. The calculation is shown in Equation 8:

$$
\text { Global Moran's } I=\frac{\sum_{i=1}^{n} \sum_{j=1}^{n} W_{i j}\left(Y_{i}-\bar{Y}\right)\left(Y_{j}-\bar{Y}\right)}{S^{2} \sum_{i=1}^{n} \sum_{j=1}^{n} W_{i j}}
$$

283

284

285

286

\begin{tabular}{cccccc}
\hline Year & Moran's I & $\mathbf{E}(\mathbf{I})$ & $\mathbf{s d}(\mathbf{I})$ & $\boldsymbol{z}$ & $\boldsymbol{p}$ \\
\hline 2000 & 0.425 & -0.050 & 0.143 & 3.327 & 0.000 \\
2001 & 0.458 & -0.050 & 0.142 & 3.572 & 0.000 \\
2002 & 0.451 & -0.050 & 0.139 & 3.613 & 0.000 \\
2003 & 0.425 & -0.050 & 0.138 & 3.455 & 0.000 \\
2004 & 0.468 & -0.050 & 0.141 & 3.663 & 0.000 \\
2005 & 0.496 & -0.050 & 0.142 & 3.845 & 0.000 \\
2006 & 0.492 & -0.050 & 0.144 & 3.752 & 0.000 \\
2007 & 0.508 & -0.050 & 0.143 & 3.890 & 0.000 \\
2008 & 0.519 & -0.050 & 0.146 & 3.906 & 0.000 \\
2009 & 0.487 & -0.050 & 0.146 & 3.669 & 0.000 \\
2010 & 0.498 & -0.050 & 0.147 & 3.735 & 0.000 \\
2011 & 0.484 & -0.050 & 0.146 & 3.655 & 0.000 \\
2012 & 0.455 & -0.050 & 0.146 & 3.466 & 0.000 \\
2013 & 0.452 & -0.050 & 0.146 & 3.444 & 0.000 \\
2014 & 0.416 & -0.050 & 0.146 & 3.200 & 0.000 \\
2015 & 0.417 & -0.050 & 0.146 & 3.200 & 0.001 \\
2016 & 0.382 & -0.050 & 0.147 & 2.951 & 0.002 \\
2017 & 0.378 & -0.050 & 0.144 & 2.976 & 0.001 \\
\hline
\end{tabular}

287

As shown above, the maximum value of Moran's I is 0.519 (2008), and the where $\boldsymbol{W}_{\boldsymbol{i} \boldsymbol{j}}$ is the spatial weight matrix, and $\boldsymbol{Y}_{\boldsymbol{i}}$ and $\boldsymbol{Y}_{\boldsymbol{j}}$ represent the carbon emissions of province $\boldsymbol{i}$ and province $\boldsymbol{j}$ in a certain year, respectively. The results are presented in

\section{Table 3.}

Table 3. Global Moran's I of carbon emissions in 21 provinces.

288 minimum value is $0.378(2017)$, both are significant $(p<0.01)$. This shows that the 
spatial agglomeration characteristics. In addition to using Moran's I to judge the spatial autocorrelation between the areas from a global perspective, the paper also explores the spatial correlation of regional carbon emissions by calculating the local Moran's I (Equation 9) and drawing a local Moran scatter plot.

$$
\text { Local Moran's } I=T_{i} \sum_{i \neq j}^{n} W_{i j} T_{j}
$$

where $\boldsymbol{T}_{\boldsymbol{i}}=\boldsymbol{Y}_{\boldsymbol{i}}-\overline{\boldsymbol{Y}}, \boldsymbol{T}_{\boldsymbol{j}}=\boldsymbol{Y}_{\boldsymbol{j}}-\overline{\boldsymbol{Y}}$, and $\boldsymbol{n}$ is the sample size.

It is generally known that there are four types of local Moran scatter plots - namely, HH agglomeration, low-high (LH) agglomeration, LL agglomeration, and high-low (HL) agglomeration - and they are located in four quadrants (Fig. 2). The HH and LL agglomerations refer to high values that surround each other or low values that surround each other, and they are positively correlated. In contrast, the LH and HL agglomerations are low values surrounded by high values, or high values surrounded by low values, respectively, which are negatively correlated.

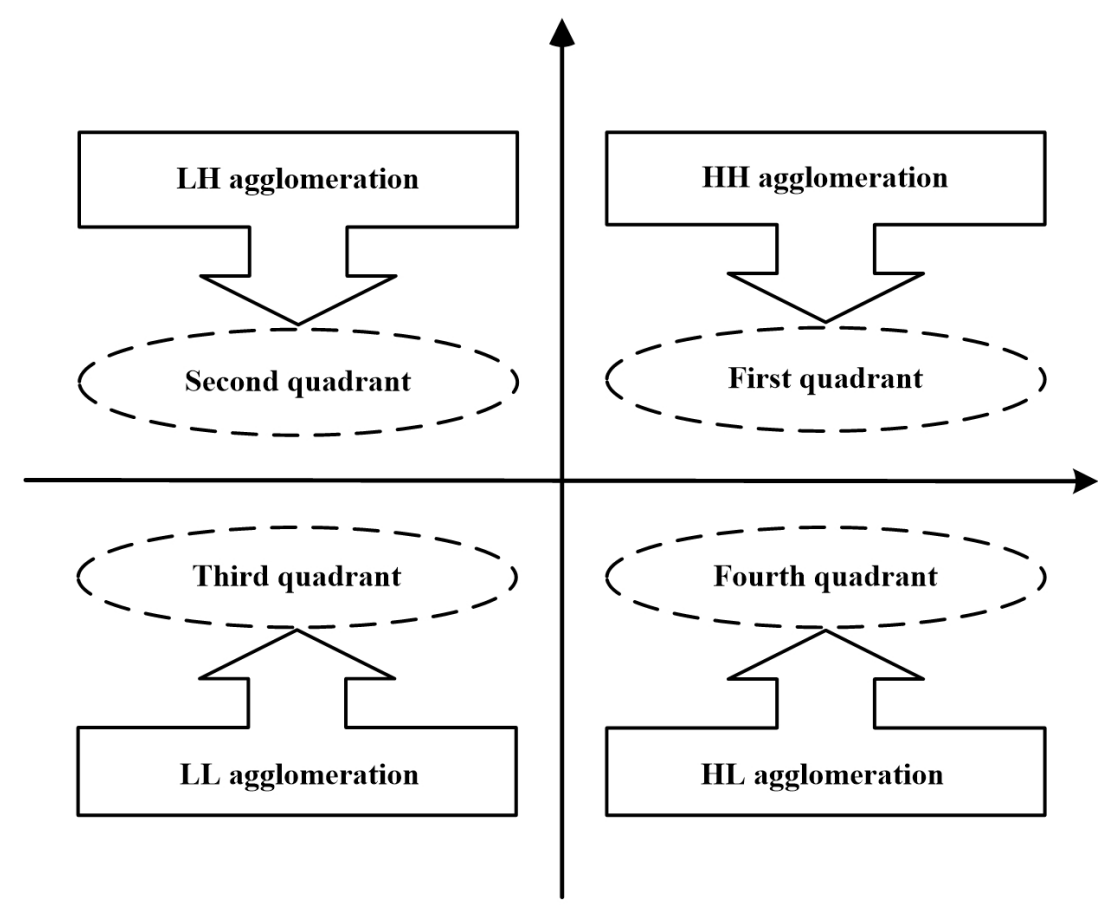

Fig. 2. Local Moran scatter plot classification.

Using Equation 9, the paper presents local spatial autocorrelation test results of carbon dioxide for some key years, such as 2000 (a), 2003 (b), 2006 (c), 2009 (d), 2012 
(e), and 2015 (f), as shown in Fig. 3. These observations reveal that most provinces are distributed in the first and third quadrants, which present typical $\mathrm{HH}$ and LL characteristics of spatial agglomeration. This indicates that there is a significant positive correlation between inter-provincial carbon emissions in the study area, which provides the necessary support for us to utilize SDM for further research.

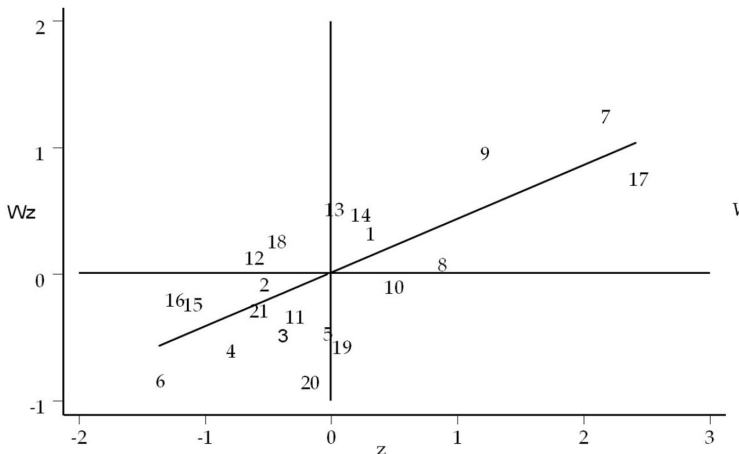

a

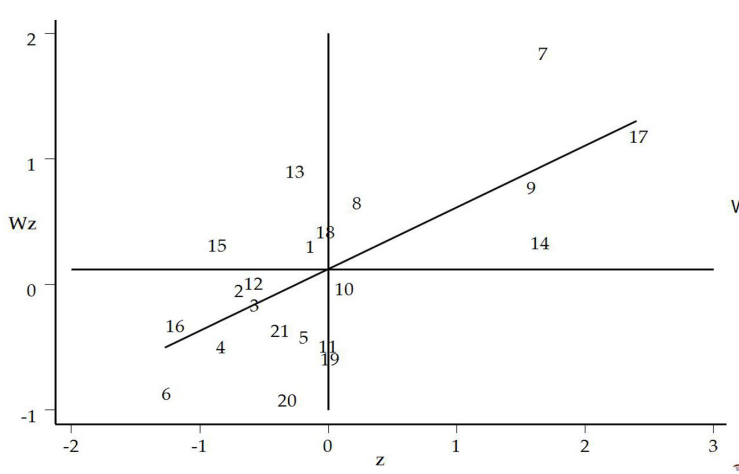

C

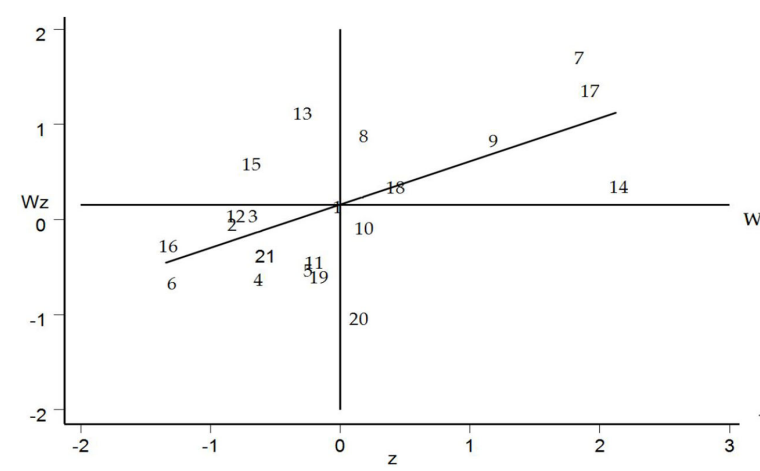

$\mathrm{e}$

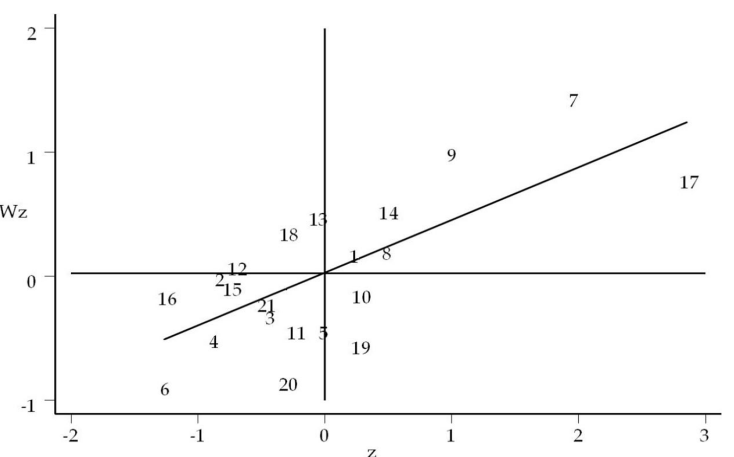

$\mathrm{b}$

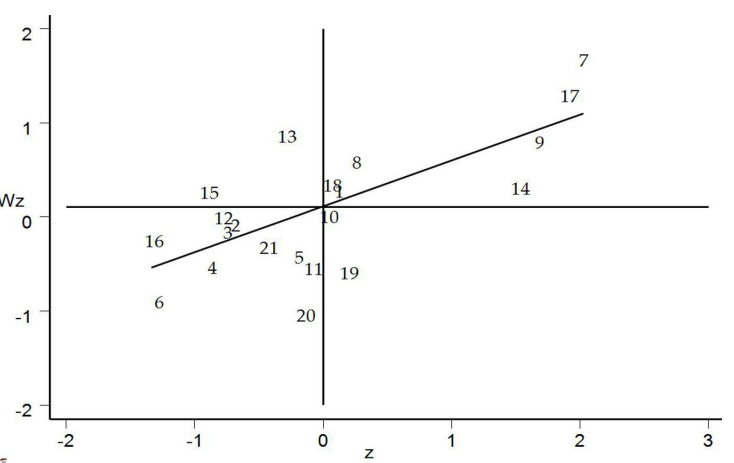

d

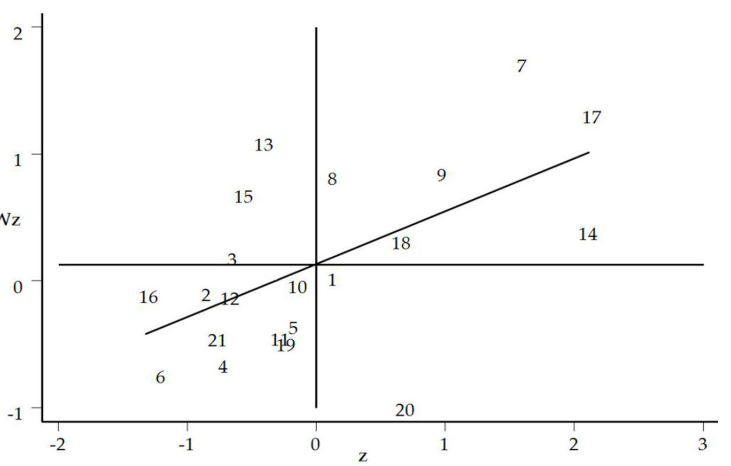

$\mathrm{f}$
312

Fig. 3. Local spatial autocorrelation test results of carbon dioxide in 2000 (a), 2003 (b), 2006 (c), 2009 (d), 2012 (e), and 2015 (f).

\subsection{Hypothesis Testing}


Currently, three methods are used to infer the full samples under different hypothesis-testing conditions. They are the Wald test, the Likelihood Ratio (LR) test, and the Lagrange Multiplier (LM). Generally speaking, the stability of the Wald test is superior to that of the LR test and LM, and the LR test is better than the LM. Considering stability, reliability and referring to the existing literature, the Wald test and LR test were selected to analyse the sample data in this study.

The results show that the values of Wald_spatial_lag, LR_spatial_lag, Wald_spatial_error, and LR_spatial_error are 25.8815, 16.2003, 5.6880 and 6.2826, and all are significant at the $1 \%$ level. Thus, the null hypothesis, $H_{0}$, was rejected. Because the spatial lag term and spatial error term were used, it was appropriate to choose the SDM.

After selecting the SDM, it was imperative to determine whether fixed effects or random effects should be used. For this, the study utilized the Hausman test. The results indicate that the Chi-square value is $47.37(p<0.01)$, thus, using fixed effects is the better option.

\subsection{Empirical Analysis of SDM under Different Spatial Matrices}

\subsubsection{Pooled OLS Estimation}

The estimation results in Table 4 show that, in the pooled OLS estimation, the value of the robust LM with no spatial lag is 0.2582 , which is not significant. While the robust LM with no spatial error shows the opposite, the statistic is $61.1495(p<0.01)$. This means that, although there is a robust spatial lag order in the sample data, it does not constitute spatial lag correlation. Thus, it is not comprehensive to study the impact of renewable energy development on carbon emissions in less-developed areas only from the linear static perspective. To some extent, this also explains the necessity of using SDM rather than a spatial error model or spatial lag model. As a result, SDM is the most suitable method for this study.

Table 4. Estimation of the non-spatial panel model (pooled OLS). 


\begin{tabular}{|c|c|c|c|c|c|}
\hline \multicolumn{2}{|c|}{ Variables } & Pooled OLS & $\begin{array}{c}\text { Spatial fixed } \\
\text { effects }\end{array}$ & $\begin{array}{c}\text { Time fixed } \\
\text { effects }\end{array}$ & $\begin{array}{l}\text { Spatial and time } \\
\text { fixed effects }\end{array}$ \\
\hline \multicolumn{2}{|c|}{$\ln c b$} & $\begin{array}{c}2.9763 \\
(0.5256)\end{array}$ & l & I & 1 \\
\hline \multicolumn{2}{|c|}{$\ln p g d p$} & $\begin{array}{c}0.4054^{* * *} \\
(3.5513)\end{array}$ & $\begin{array}{c}0.3831 * * * \\
(3.4233)\end{array}$ & $\begin{array}{c}0.1951 \\
(1.2610)\end{array}$ & $\begin{array}{c}0.1351 \\
(0.8938)\end{array}$ \\
\hline \multicolumn{2}{|c|}{$\ln n e c$} & $\begin{array}{c}-0.2028 * * * \\
(-14.6340)\end{array}$ & $\begin{array}{l}-0.2048 * * * \\
(-15.0404)\end{array}$ & $\begin{array}{c}-0.2544 * * * \\
(-13.6895)\end{array}$ & $\begin{array}{c}-0.2684 * * * \\
(-14.6306)\end{array}$ \\
\hline \multicolumn{2}{|c|}{$\ln u r$} & $\begin{array}{c}-0.6227 * * * \\
(-2.9319)\end{array}$ & $\begin{array}{c}-0.5500^{* * *} \\
(-2.6317)\end{array}$ & $\begin{array}{l}-0.4422 * * \\
(-2.0528)\end{array}$ & $\begin{array}{l}-0.3067 \\
(-1.4625)\end{array}$ \\
\hline \multicolumn{2}{|c|}{$\ln i r$} & $\begin{array}{c}1.1743 * * * \\
(8.9136)\end{array}$ & $\begin{array}{c}1.2347 * * * \\
(9.4630)\end{array}$ & $\begin{array}{c}1.0817 * * * \\
(6.8942)\end{array}$ & $\begin{array}{c}1.2119 * * * \\
(7.8106)\end{array}$ \\
\hline \multicolumn{2}{|c|}{$\ln h c$} & $\begin{array}{l}-0.0537 \\
(-0.4414)\end{array}$ & $\begin{array}{l}-0.0193 \\
(-0.1613)\end{array}$ & $\begin{array}{l}-0.0671 \\
(-0.5277)\end{array}$ & $\begin{array}{l}-0.0377 \\
(-0.3044)\end{array}$ \\
\hline \multicolumn{2}{|c|}{$\ln p c$} & $\begin{array}{c}0.2037 * * * \\
(6.1461)\end{array}$ & $\begin{array}{c}0.2120^{* * *} \\
(6.5159)\end{array}$ & $\begin{array}{c}0.1836^{* * *} \\
(4.8122)\end{array}$ & $\begin{array}{c}0.2007 * * * \\
(5.4331)\end{array}$ \\
\hline \multicolumn{2}{|c|}{$\ln t y$} & $\begin{array}{c}-0.0010 \\
(-0.0210)\end{array}$ & $\begin{array}{c}-0.0190 \\
(-0.3867)\end{array}$ & $\begin{array}{c}0.1448 * * \\
(2.4986)\end{array}$ & $\begin{array}{c}0.1280 * * \\
(2.2706)\end{array}$ \\
\hline \multirow{2}{*}{$\begin{array}{l}\text { No spatial } \\
\text { lag }\end{array}$} & LM & $19.9185^{* * *}$ & $19.2465^{* * *}$ & 2.4281 & 1.8921 \\
\hline & Robust LM & 0.2582 & 0.4034 & 0.4336 & 0.5151 \\
\hline \multirow{2}{*}{$\begin{array}{c}\text { No spatial } \\
\text { error }\end{array}$} & LM & $80.8098^{* * *}$ & $84.7400^{* * *}$ & $11.5649^{* * *}$ & $10.7858 * * *$ \\
\hline & Robust LM & $61.1495^{* * *}$ & $65.8970 * * *$ & $9.5704 * * *$ & $9.4088^{* * *}$ \\
\hline \multicolumn{2}{|c|}{$\mathrm{R}^{2}$} & 0.8147 & 0.8216 & 0.7616 & 0.7768 \\
\hline
\end{tabular}

Note: $t$-statistics of the coefficients are in parentheses; $*, * *, * * *$ indicate significant levels at $10 \%, 5 \%$, and $1 \%$, respectively.

\subsubsection{Analysis of the SDM}

Using MATLAB 2018a-econometric and statistical analysis software-under spatial fixed effects, time fixed effects, spatial and time fixed effects, and $\boldsymbol{W}_{\boldsymbol{l}}, \boldsymbol{W}_{2}$, and $\boldsymbol{W}_{3}$ spatial weight matrices, we uses SDM to analyse the spatial spillover effects of renewable energy on carbon emissions in China's less-developed areas with eight variables. The results are as follows.

Compared with spatial fixed effects and time fixed effects, the spatial and time double fixed effects method is the most scientific for panel data analysis, and the results are also more referential. Therefore, we used the results from the spatial and time double fixed effects method to carry out the analysis. As shown in Table 5, in the matrix of $\boldsymbol{W}_{1}, \boldsymbol{W}_{2}$, and $\boldsymbol{W}_{3}$, the coefficients for per capita GDP are $0.1525,5.2484$ and 0.1028 , 
356 respectively ( $p>0.05$ for all). This indicates that per capita GDP growth in the 21 less-

357 developed provinces correlates with the increase of carbon emissions, but this effect is

358 not significant now. Meanwhile, the coefficients for renewable energy consumption are

$359-0.2652,-0.2676$, and -0.2653 , respectively $(p<0.01$ for all). This means that renewable

360 energy development in less-developed areas can inhibit carbon emissions, and this

361 effect is extremely significant.

Table 5. Results of SDM under different spatial weight matrices.

\begin{tabular}{|c|c|c|c|c|c|c|c|c|c|}
\hline \multirow{2}{*}{ Variables } & \multicolumn{3}{|c|}{ Spatial fixed effects } & \multicolumn{3}{|c|}{ Time fixed effects } & \multicolumn{3}{|c|}{ Spatial and time fixed effects } \\
\hline & $W_{1}$ & $W_{2}$ & $W_{3}$ & $W_{1}$ & $W_{2}$ & $W_{3}$ & $W_{1}$ & $W_{2}$ & $W_{3}$ \\
\hline \multirow{2}{*}{$\ln p g d p$} & 0.1622 & 0.1643 & 0.1518 & 0.2151 & 0.1447 & 0.1307 & 0.1525 & 5.2484 & 0.1028 \\
\hline & $(1.1062)$ & $(1.0861)$ & $(1.0023)$ & (1.3997) & $(0.8648)$ & $(0.7884)$ & $(0.9891)$ & $(0.5045)$ & $(0.4221)$ \\
\hline \multirow{2}{*}{$\ln n e c$} & $-0.2580 * * *$ & $-0.2688 * * *$ & $-0.2642 * * *$ & $-0.2536 * * *$ & $-0.2521 * * *$ & $-0.2500 * * *$ & $-0.2652 * * *$ & $-0.2676^{* * *}$ & $-0.2653 * * *$ \\
\hline & $(-13.6404)$ & $(-14.4977)$ & $(-14.1670)$ & $(-13.3281)$ & $(-13.0926)$ & $(-13.0362)$ & $(-13.7499)$ & $(-13.6409)$ & $(-13.5910)$ \\
\hline \multirow{2}{*}{$\ln u r$} & $-0.3975^{*}$ & -0.3320 & -0.3278 & $-0.5063 * *$ & -0.3519 & -0.3517 & $-0.3762 *$ & -0.2229 & -0.2229 \\
\hline & $(-1.9082)$ & $(-1.5846)$ & $(-1.5623)$ & $(-2.3604)$ & $(-1.5212)$ & $(-1.5258)$ & $(-1.7606)$ & $(-0.9640)$ & $(-0.9688)$ \\
\hline \multirow{2}{*}{$\ln i r$} & $1.4016^{* * *}$ & $1.2432 * * *$ & $1.2526^{* * *}$ & $1.1374 * * *$ & $1.0899 * * *$ & $1.0964 * * *$ & $1.2854 * * *$ & $1.2171^{* * *}$ & $1.2287 * * *$ \\
\hline & $(9.1166)$ & $(7.9686)$ & $(7.9322)$ & $(7.2287)$ & $(6.6433)$ & $(6.7122)$ & $(8.0321)$ & $(7.3445)$ & $(7.4623)$ \\
\hline \multirow{2}{*}{$\ln h c$} & -0.0691 & -0.0592 & -0.0471 & -0.1050 & -0.0195 & -0.0029 & -0.0772 & 0.0060 & 0.0216 \\
\hline & $(-0.5657)$ & $(-0.4740)$ & $(-0.3751)$ & $(-0.8341)$ & $(-0.1445)$ & $(-0.0217)$ & $(-0.6143)$ & $(0.0448)$ & $(0.1612)$ \\
\hline \multirow{2}{*}{$\ln p c$} & $0.2256^{* * *}$ & $0.1998 * * *$ & $0.2048^{* * *}$ & $0.1914^{* * *}$ & $0.1885^{* * *}$ & $0.1923 * * *$ & $0.2106^{* * *}$ & $0.2076 * * *$ & $0.2124 * * *$ \\
\hline & $(6.0471)$ & $(5.3515)$ & $(5.4570)$ & $(5.0111)$ & $(4.6829)$ & $(4.8192)$ & $(5.5448)$ & $(5.1700)$ & $(5.3365)$ \\
\hline \multirow{2}{*}{$\ln t y$} & 0.0878 & $0.1210^{* *}$ & $0.1138^{* *}$ & $0.1364 * *$ & $0.1428^{* *}$ & $0.1391 * *$ & $0.1185^{* *}$ & $0.1252 * *$ & $0.1202 * *$ \\
\hline & $(1.5121)$ & $(2.0975)$ & (1.9808) & $(2.3278)$ & $(2.3901)$ & $(2.3280)$ & $(2.0195)$ & $(2.0974)$ & $(2.0182)$ \\
\hline \multirow{2}{*}{$W^{*} \ln p g d p$} & 0.0221 & -0.2244 & -0.0102 & 0.0309 & -0.8146 & -1.2238 & 0.0252 & -0.8948 & -1.2891 \\
\hline & $(0.1253)$ & $(-1.0077)$ & $(-0.0456)$ & $(0.1066)$ & $(-0.7605)$ & $(-1.2404)$ & $(0.0881)$ & $(-0.8431)$ & $(-1.3193)$ \\
\hline \multirow{2}{*}{$W^{*} \ln n e c$} & $0.1629 * * *$ & $0.2066^{* * *}$ & $0.2064 * * *$ & $0.0758^{*}$ & -0.0228 & -0.0129 & $0.0855^{* *}$ & -0.0015 & -0.0122 \\
\hline & $(6.5281)$ & (7.8063) & $(8.3123)$ & (1.9401) & $(-0.1790)$ & $(-0.1066)$ & $(2.1612)$ & $(-0.0117)$ & $(-0.0973)$ \\
\hline \multirow{2}{*}{$W^{*} \ln u r$} & 0.1371 & 0.5618 & 0.3467 & 0.1591 & 2.0086 & $2.3693 *$ & 0.1861 & 2.0798 & $2.3800^{*}$ \\
\hline & $(0.4563)$ & (1.3380) & $(0.8548)$ & $(0.3914)$ & (1.3569) & (1.6808) & $(0.4632)$ & $(1.3921)$ & $(1.6732)$ \\
\hline \multirow{2}{*}{$W^{*} \ln i r$} & $-0.7988 * * *$ & $-0.7796^{* * *}$ & $-0.6872 * * *$ & $-0.9134 * * *$ & -0.7224 & -1.2414 & $-1.0366^{* * *}$ & -1.1960 & -1.6240 \\
\hline & $(-3.9409)$ & $(-3.4378)$ & $(-3.0126)$ & $(-2.9778)$ & $(-0.7087)$ & $(-1.1885)$ & $(-3.3307)$ & $(-1.1604)$ & $(-1.5357)$ \\
\hline \multirow{2}{*}{$W^{*} \ln h c$} & 0.0939 & 0.3220 & 0.1280 & 0.0678 & 0.7700 & 1.2120 & 0.0626 & 0.7655 & 1.1805 \\
\hline & $(0.5444)$ & (1.3110) & $(0.5272)$ & $(0.2960)$ & $(0.8980)$ & (1.4666) & $(0.2767)$ & $(0.9022)$ & $(1.4406)$ \\
\hline \multirow{2}{*}{$W^{*} \ln p c$} & $-0.1136^{*}$ & -0.0228 & -0.0800 & $-0.1278^{*}$ & -0.0424 & -0.0709 & $-0.1399 * *$ & -0.0747 & -0.0815 \\
\hline & $(-2.2586)$ & $(-0.2684)$ & $(-1.0310)$ & $(-1.7656)$ & $(-0.1612)$ & $(-0.3023)$ & $(-1.9551)$ & $(-0.2867)$ & $(-0.3511)$ \\
\hline \multirow{2}{*}{$W^{*} \ln t y$} & -0.1157 & $-0.2257 * *$ & $-0.2158 * *$ & 0.0455 & 0.1559 & 0.2419 & 0.0327 & 0.1649 & 0.2479 \\
\hline & $(-1.5486)$ & $(-2.2451)$ & $(-2.1358)$ & $(0.4323)$ & $(0.4327)$ & $(0.7093)$ & $(0.3129)$ & $(0.4605)$ & $(0.7306)$ \\
\hline \multirow{2}{*}{$W^{*} \ln c b$} & $0.5020^{* * *}$ & $0.6180^{* * *}$ & $0.6080^{* * *}$ & $0.2350 * * *$ & -0.1000 & -0.0500 & $0.3072 * * *$ & 0.1172 & 0.1108 \\
\hline & $(10.1396)$ & (11.2231) & $(10.7682)$ & (3.8262) & $(-0.8814)$ & $(-0.5223)$ & (5.2484) & $(1.2348)$ & (1.3419) \\
\hline $\mathrm{R}^{2}$ & 0.8727 & 0.8698 & 0.8686 & 0.8747 & 0.8676 & 0.8685 & 0.8854 & 0.8782 & 0.8795 \\
\hline
\end{tabular}




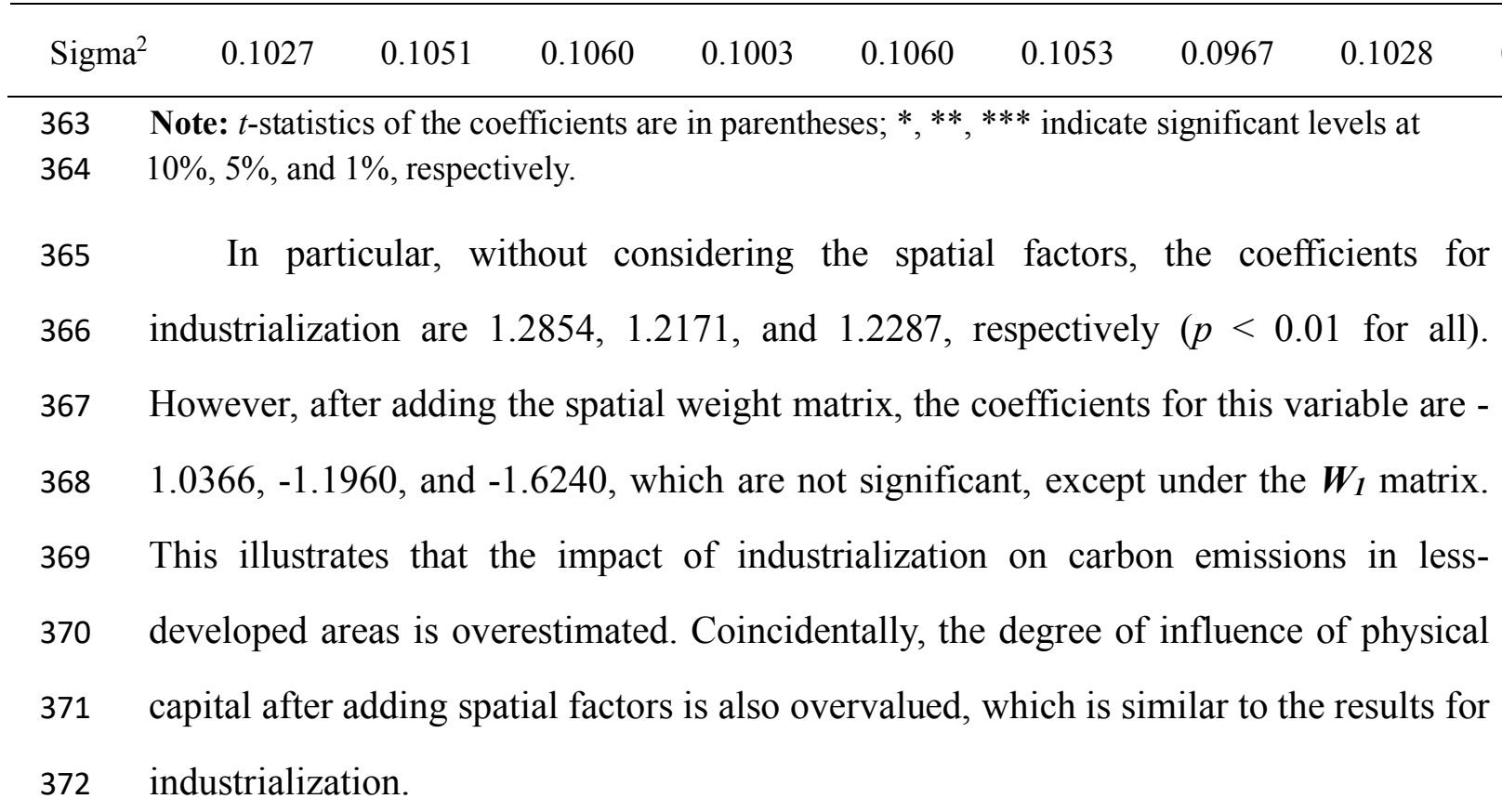

\subsubsection{Analysis of the Direct and Indirect Effects}

\section{- Direct effects}

As displayed in Table 6, under the $\boldsymbol{W}_{1}, \boldsymbol{W}_{2}$ and $\boldsymbol{W}_{3}$ matrices, the coefficients of per capita GDP are $0.1755,0.1426$ and 0.1633 , but none of them pass the $10 \%$ significance test, indicating that per capita GDP has a positive impact on carbon emissions in China's less-developed areas, but this effect is not significant. However, the coefficients of renewable energy consumption are $-0.2522,-0.2639$ and -0.2601 , and all pass the $1 \%$ significance test. It appears that renewable energy has a significant effect on reducing carbon emissions in the region. In addition, we can also find that the coefficients of industrialization and physical capital are also positive, and both pass the $1 \%$ significance test, which shows that as industrial production efficiency and social physical capital increases, carbon emissions are also increasingly, and the positive effects are highly significant.

\section{- Indirect effects (Spatial spillover)}

The possible spillover coefficients of per capita GDP are 0.1889 and 0.2011 under the $\boldsymbol{W}_{l}$ and $\boldsymbol{W}_{3}$ matrices, respectively $(p>0.10)$. That is, the increase of per capita GDP 
has a positive spatial spillover effect on carbon emissions in neighbouring areas, but this effect is not significant in the adjacency matrix and the gravity model matrix. In the meantime, it's not difficult for us to find that the spillover coefficient of in $\boldsymbol{W}_{2}$ matrix is $-0.3004(p>0.10)$, this indicates that, there is a negative correlation between per capita GDP and carbon emissions in adjacent areas. However, the negative relationship is still not obvious.

According to the results of empirical analysis in Table 6, the estimated spillover coefficients for renewable energy consumption in the $\boldsymbol{W}_{1}, \boldsymbol{W}_{2}$ and $\boldsymbol{W}_{3}$ matrices are $0.0605,0.1012$ and 0.1125 , suggesting that higher renewable energy consumption in a single area is conducive to the improvement of carbon emissions to neighbouring areas. The main reasons for this are as follows: first, under the pressure of ecological protection, although the proportion of renewable energy in the overall energy structure of less-developed areas has increased, its consumption scale is still far behind that of fossil energy. Second, key factors such as technological innovations, service guarantees, and infrastructure construction related to renewable energy are imperfect, leading to their slow application in China's less-developed areas. Third, related industries of renewable energy are still in the primary stages, and the spatial effect of renewable energy on regional carbon emissions reduction has not been fully exerted. What is beyond doubt is that there is a long way to go before renewable energy can completely replace the traditional fossil fuels in some basic industries, including chemical processing, steel, paper, and other fields with high energy consumption and high carbon emissions.

Based on the calculation results of direct effects and indirect effects, this paper also analyzes the control variables of carbon emissions. For example, the estimated values of human capital are $0.1179,0.7149$ and 0.2307 , this means that, with the increase of local human capital, carbon emissions in neighboring areas are also increasing. In contract, the coefficients of technological innovation are $-0.1366,-0.3768$ and -0.3493 , with only the values in the $\boldsymbol{W}_{2}$ and $\boldsymbol{W}_{3}$ matrices pass the $10 \%$ significance test, indicating that technological innovation has a positive effect to reduce carbon 
emissions. Therefore, more attention should be paid to technological innovation in China's less-developed areas, especially renewable energy utilization technology.

Table 6. Estimation results of the direct and indirect effects.

\begin{tabular}{ccccccc}
\hline \multirow{2}{*}{ Variables } & \multicolumn{3}{c}{ Direct effects } & \multicolumn{3}{c}{ Indirect effects (Spatial spillover) } \\
\cline { 2 - 7 } & $\boldsymbol{W}_{\boldsymbol{I}}$ & $\boldsymbol{W}_{\boldsymbol{2}}$ & $\boldsymbol{W}_{3}$ & $\boldsymbol{W}_{\boldsymbol{1}}$ & $\boldsymbol{W}_{\mathbf{2}}$ & $\boldsymbol{W}_{3}$ \\
\hline \multirow{2}{*}{$\ln p g d p$} & 0.1755 & 0.1426 & 0.1633 & 0.1889 & -0.3004 & 0.2011 \\
& $(1.2249)$ & $(0.9870)$ & $(1.1192)$ & $(0.7264)$ & $(-0.6526)$ & $(0.4505)$ \\
$\ln n e c$ & $-0.2522^{* * *}$ & $-0.2639^{* * *}$ & $-0.2601^{* * *}$ & $0.0605^{*}$ & $0.1012^{*}$ & $0.1125^{* * *}$ \\
& $(-13.6337)$ & $(-14.5218)$ & $(-14.2578)$ & $(2.0154)$ & $(2.1693)$ & $(2.7116)$ \\
$\ln u r$ & $-0.3977^{*}$ & -0.2880 & -0.3141 & -0.1077 & 0.8932 & 0.3412 \\
& $(-1.9004)$ & $(-1.4109)$ & $(-1.4416)$ & $(-0.2154)$ & $(0.9090)$ & $(0.3589)$ \\
$\ln i r$ & $1.3934 * * *$ & $1.2397 * * *$ & $1.2623^{* * *}$ & -0.1740 & -0.0186 & 0.1664 \\
& $(9.7874)$ & $(8.1872)$ & $(7.7902)$ & $(-0.6023)$ & $(-0.0395)$ & $(0.4064)$ \\
$\ln h c$ & -0.0544 & -0.0209 & -0.0406 & 0.1179 & 0.7149 & 0.2307 \\
& $(-0.4353)$ & $(-0.1681)$ & $(-0.3213)$ & $(0.4034)$ & $(1.2557)$ & $(0.4172)$ \\
$\ln p c$ & $0.2254^{* * *}$ & $0.2138^{* * *}$ & $0.2088^{* * *}$ & -0.0001 & 0.2441 & 0.1078 \\
& $(6.0489)$ & $(5.6103)$ & $(5.5072)$ & $(-0.0024)$ & $(1.2662)$ & $(0.5871)$ \\
$\ln t y$ & 0.0748 & $0.1027 *$ & $0.0990^{*}$ & -0.1366 & $-0.3768^{*}$ & $-0.3493^{*}$ \\
& $(1.3081)$ & $(1.8025)$ & $(1.7200)$ & $(-1.1819)$ & $(-1.7084)$ & $(-1.6140)$ \\
\hline
\end{tabular}

Note: $t$-statistics of the coefficients are in parentheses; $*, * *, * * *$ indicate significant levels at $10 \%, 5 \%$, and $1 \%$, respectively.

\section{Discussion}

Using provincial panel data and SDM, this paper studies the spatial spillover effects of renewable energy development on carbon emissions in China's lessdeveloped areas with the help of three spatial weight matrices. we finds that, although carbon emissions in China's less-developed areas are highly clustered now, but renewable energy cannot replace fossil energy completely, and the positive effect on carbon emission reduction is not fully revealed. Therefore, it is necessary to develop and utilize renewable energy to reduce carbon emissions in the process of agricultural, industrial and service development, enhance the agglomeration effect of renewable energy in the high-quality development of regional economies. The primary conclusions of this research provide references for the further study of renewable energy, and support for governments and relevant organizations to formulate renewable energy 
policies around the world.

The contribution of this paper is two-fold: first, for the evaluation of the spatial spillover effects of renewable energy on carbon emissions, previous studies are based on a single spatial weight matrix, but this paper expands the spatial weight matrix to three. Second, scholars have conducted extensive research on the carbon emissions effects of renewable energy from the perspective of urban and rural areas, but few literatures on this issue of less-developed areas from the provincial scale. This is another small contribution of this study.

This paper highlights China's less-developed areas, but the research conclusions and policy recommendations may not be applicable to other similar areas of the world. This is where the research may need further improvement. Therefore, future work should gradually expand the scope of the research, and collect and sort out relevant data to further enrich our research conclusions and policy implications.

\section{Conclusions and Policy Implications}

\subsection{Conclusions}

In China's less-developed regions, Moran's I for carbon emissions are between 0.378 and 0.518 . This shows that the carbon emissions of the study area have typical agglomeration characteristics and significant spatial correlation. This is the basis of empirical research that uses spatial econometrics methods.

Moreover, by using SDM and its decomposition method based on three kinds of spatial weight matrices, the research finds that, the direct effect coefficients of renewable energy are $-0.2522,-0.2639$ and -0.2601 , this shows that renewable energy is beneficial to regional carbon emissions reduction. The indirect effect coefficients of renewable energy are $0.0605,0.1012$ and 0.1125 , which means higher renewable energy consumption in a single area is conducive to the improvement of carbon emissions to neighbouring areas.

Last, control variables such as per capita GDP, technological innovation, industrialization, and urbanization, have spatial spillover effects on carbon emissions, 
but the effects are different. Thus, policy makers must formulate specific measures according to the role of each control variable.

\subsection{Policy Implications}

On the basis of the estimated results, in view of the problems found in the study, and to maximize the spatial spillover effects of renewable energy in carbon emissions reduction, the following policy suggestions are offered.

- Policy makers should be aware of formulating an integrated development strategy for renewable energy. They should encourage more renewable energy producers and consumers to deploy in less-developed areas - not only in China, but also in similar world regions - and expand the scale of renewable energy industries to avoid homogeneous competition. Our goal is to guide the development of renewable energy to curb carbon emissions through rational policies.

- The industrial structures of China's less-developed areas should be reformed in a clean way as soon as possible. Traditional industries with high energy consumption and per-unit output, heavy pollution should be eliminated. Governments should support the construction of modern green industry systems of renewable energy, minimize the spatial transfer of carbon emissions in the process of industrial production, and achieve sustainable development.

- Technological innovation is the key factor to reducing carbon emissions in China's less-developed areas. On the one hand, government and related organizations must increase investment in renewable energy development and utilization technology, improve R\&D infrastructure of renewable energy, and gradually replace traditional fossil energy. On the other hand, it would be beneficial to strengthen the cultivation of renewable energy talents, and to provide continuous intellectual support to the development of China's renewable energy technology innovations. The purpose is to provide diversified renewable energy products and services for demand sides, and expand the positive spillover effect of technological innovation on regional carbon emission reduction. 
- Appropriately improving the level of urban construction is another essential

492

493

494

495

496

497

498

499

500

501

502

503

504

505

506

507

508

509

510

511

512

513

514

515

516

measure for carbon emissions reduction in China's less-developed areas. Moderate urbanization not only reduces the cost of renewable energy consumption, but also provides sustainable energy supply for the development of China's central and western regions, and minimizes the carbon emissions caused by the excessive use of fossil energy. This is important for China to meet their carbon emissions reduction commitment in the Paris Agreement by 2030, and to help deal with the growing global climate crisis.

- Increasing people's awareness of using renewable energy is an effective way to reduce carbon emissions. As the largest country in terms of RES and population, the Chinese government has the responsibility to enhance citizens' awareness of renewable energy, especially in remote and poor areas of China. On the one hand, it can reflect China's specific actions to mitigate carbon emissions.

Authors' contributions Jun Bai: conceptualization, methodology, software, data curation, validation, formal analysis, writing-original draft. Shixiang Li: conceptualization, methodology, resources, writing-review and editing, project administration, supervision. Qiying Kang: software. Nan Wang: data curation. Kailu Guo: visualization. Jinfeng Wang: investigation. Jinhua Cheng: resources.

Funding The work was supported by the National Natural Science Foundation of China under Grant No.71991482, by the National Social Science Fund of China under Grant No.16BJY049, and by the Special Fund for Basic Scientific Research of Central Colleges under Grant No.CUG170105.

Data Availability The datasets used and analysed during the current study are available from the corresponding author on reasonable request.

\section{Declarations}


517 Ethics approval and consent to participate Not applicable.

518 Consent for publication Not applicable.

519 Competing interests The authors declare no competing interests.

520 Authors' information (optional) Not applicable.

\section{References}

Acheampong AO, Adams S, Boateng E (2019) Do globalization and renewable energy contribute to carbon emissions mitigation in Sub-Saharan Africa? Sci Total Environ 677:436-446. https://doi.org/10.1016/j.scitotenv.2019.04.353

Adam S, Nsiah C (2019) Reducing carbon dioxide emissions: Does renewable energy matter? Sci Total Environ 693:133288. https://doi.org/10.1016/j.scitotenv.2019.07.094

Ajani JI, Keith H, Blakers M, Mackey BG, King HP (2013) Comprehensive carbon stock and flow accounting: A national framework to support climate change mitigation policy. Ecol Econ 89:61-73. https://doi.org/10.1016/j.ecolecon.2013.01.010

Al-mulali U, Tang CF (2013) Investigating the validity of pollution haven hypothesis in the gulf cooperation council (GCC) countries. Energy Pol 60:813-819. https://doi.or g/10.1016/j.enpol.2013.05.055

Baek J (2015) Environmental Kuznets curve for $\mathrm{CO}_{2}$ emissions: The case of Arctic countries. Energy Econ 50:13-17. https://doi.org/10.1016/j.eneco.2015.04.010

Berk I, Kasman A, Kılınç D (2018) Towards a common renewable future: The System-GMM approach to assess the convergence in renewable energy consumption of EU countries. Energy Econ 87:103922. https://doi.org/10.1016/j.eneco.2018.02.013

Bermudez-Edo M, Barnaghi P, Moessner K (2018) Analysing real world data streams with spatio-temporal correlations: Entropy vs. Pearson correlation. Aut Constr 88:87-100. https://doi.org/10.1016/j.autcon.2017.12.036

BP (2020) Statistical Review of World Energy 2020. https://www.bp.com/en/global/corporat e/energy-economics/statistical-review-of-world-energy.html. Accessed 17 June 2020

Caviglia-Harris JL, Chambers D, Kahn JR (2009) Taking the "U" out of Kuznets: A comprehensive analysis of the EKC and environmental degradation. Ecol Econ 68: 1149- 
1159. https://doi.org/10.1016/j.ecolecon.2008.08.006

Chen SY (2011) Reconstruction of Sub-industrial Statistical Data in China (1980-2008). China Econ Q 10(3):735-776. https://doi.org/10.13821/j.cnki.ceq.2011.03.012 (In Chinese)

Cheng C, Ren XH, Wang Z, Yan C (2019) Heterogeneous impacts of renewable energy and environmental patents on $\mathrm{CO}_{2}$ emission-Evidence from the BRIICS. Sci Total Environ 668:1328-1338. https://doi.org/10.1016/j.scitotenv.2019.02.063

Cheng YY, Yao X (2021) Carbon intensity reduction assessment of renewable energy technology innovation in China: A panel data model with cross-section dependence and slopeheterogeneity. Renew Sustain Energy Rev 135:110157. https://doi.org/ 10.1016/j.rser.2020.110157

Chica-Olmo J, Salaheddine SH, Moya-Fernández P (2020) Spatial relationship between economic growth and renewable energy consumption in 26 European countries. Energy Econ 92:104962. https://doi.org/10.1016/j.eneco.2020.104962

Cole MA, Elliott RJR, Okubo T, Zhou Y (2013) The carbon dioxide emissions of firms: A spatial analysis. J Environ Econ Manag 65(2):290-309. https://doi.org/10.1016/j.jee m.2012.07.002

Dong KY, Sun RJ, Hochman G (2017) Do natural gas and renewable energy consumption lead to less $\mathrm{CO}_{2}$ emission? Empirical evidence from a panel of BRICs countries. Energy 141:1466-1478. https://doi.org/10.1016/j.energy.2017.11.092

Erdogan S (2021) Dynamic nexus between technological innovation and buildings Sector's carbon emission in BRICS countries. J Environ Manag 293:112780. https://doi.org/10. 1016/j.jenvman.2021.112780

Gao Y, Gao X, Zhang XH (2017) The $2^{\circ} \mathrm{C}$ Global Temperature Target and the Evolution of the Long-Term Goal of Addressing Climate Change-From the United Nations Framework Convention on Climate Change to the Paris Agreement. Eng 3(2):272-278. https://doi.org/10.1016/J.ENG.2017.01.022

Guo WB, Chen Y (2018) Assessing the efficiency of China's environmental regulation on carbon emissions based on Tapio decoupling models and GMM models. Energy Rep 4:713-723. https://doi.org/10.1016/j.egyr.2018.10.007 
Hansen LP (2012) Proofs for large sample properties of generalized method of moments estimators. J Econ 17(2):325-330. https://doi.org/10.1016/j.jeconom.2012.05.008

Hu H, Xie N, Fang DB, Zhang XL (2018) The role of renewable energy consumption and commercial services trade in carbon dioxide reduction: Evidence from 25 developing countries. Appl Energy 211:1229-1244. https://doi.org/10.1016/j.apenergy.2017.12.019

Jiang JJ, Ye B, Liu JG (2019) Peak of $\mathrm{CO}_{2}$ emissions in various sectors and provinces of China: Recent progress and avenues for further research. Renew Sustain Energy Rev 112:813833. https://doi.org/10.1016/j.rser.2019.06.024

Jia RN, Shao S, Yang LL (2021) High-speed rail and $\mathrm{CO}_{2}$ emissions in urban China: A spatial difference-in-differences approach. Energy Econ 99:105271. https://doi.org /10.1016/j.eneco.2021.105271

Khan A, Yang CG, Khan G, Muhammad F (2020) The dilemma of natural disasters: Impact on economy, fiscal position, and foreign direct investment alongside Belta nd Road Initiative countries. Sci Total Environ 743:140578. https://doi.org/10.1016 /j.scitotenv.2020.140578

Lau LC, Lee KT, Mohamed AR (2012) Global warming mitigation and renewable energy policy development from the Kyoto Protocol to the Copenhagen Accord-A comment. Renew Sustain Energy Rev 16(7):5280-5284. https://doi.org/10.1016/j.rser.2012.04.006

LeSage J, Pace RK (2009) Introduction to Spatial Econometrics. New York: Chemical Rubber Company (CRC) Press, Cleveland

Li JY, Li SS (2020) Energy investment, economic growth and carbon emissions in ChinaEmpirical analysis based on spatial durbin model. Energy Pol 140:111425. https://doi.org/10.1016/j.enpol.2020.111425

Li T, Li A, Guo XP (2020) The sustainable development-oriented development and utilization of renewable energy industry-A comprehensive analysis of MCDM methods. Energy 212:118694. https://doi.org/10.1016/j.energy.2020.118694

Li YL, Chen B, Chen GQ (2020) Carbon network embodied in international trade: Global structural evolution and its policy implications. Energy Pol 139:111316. https://doi.org/ 10.1016/j.enpol.2020.111316 
Liu JX, Qu JY, Zhao K (2019) Is China's development conforms to the Environmental Kuznets Curve hypothesis and the pollution haven hypothesis? J Clean Prod 234:787-796. https://doi.org/10.1016/j.jclepro.2019.06.234

López LA, Arce G, Zafrilla JE (2013) Parcelling virtual carbon in the pollution haven hypothesis. Energy Econ 39:177-186. https://doi.org/10.1016/j.eneco.2013.05.006

Mi XM, Liao HC (2020) Renewable energy investments by a combined compromise solution method with stochastic information. J Clean Prod 276:123351. https://do i.org/10.1016/j.jclepro.2020.123351

NBSC (2020) China Statistical Yearbook 2020. http://www.stats.gov.cn/tjsj/ndsj/2020/ind exeh.htm (In Chinese)

NBSC (2021) Statistical Bulletin of the National Economic and Social Development in 2021. http://www.stats.gov.cn/tjsj/zxfb/202102/t20210227_1814154.html. Accessed 28 February 2020 (In Chinese)

Ouyang XL, Lin BQ (2014) Impacts of increasing renewable energy subsidies and phasing out fossil fuel subsidies in China. Renew Sustain Energy Rev 37:933-942. https://doi.o rg/10.1016/j.rser.2014.05.013

Park BJ, Hur J (2018) Spatial prediction of renewable energy resources for reinforcing and expanding power grids. Energy 164:757-772. https://doi.org/10.1016/j.energy.2 018.09 .032

Qin QD, Liu Y, Huang JP (2020) A cooperative game analysis for the allocation of carbon emissions reduction responsibility in China's power industry. Energy Econ 92:104960. https://doi.org/10.1016/j.eneco.2020.104960

Sarkodie SA, Adams S, Leirvik T (2020) Foreign direct investment and renewable energy in climate change mitigation: Does governance matter? J Clean Prod 263:121263. https://doi.org/10.1016/j.jclepro.2020.121262.

Shahnazi R, Shahnazi ZD (2020) Do renewable energy production spillovers matter in the EU? Renew Energy 150:786-796. https://doi.org/10.1016/j.renene.2019.12.123

Shuai J, Leng ZH, Cheng JH, Shi ZY (2020) China's renewable energy trade potential in the "Belt-and-Road" countries: A gravity model analysis. Renew Energy 161:1025-1035. 
https://doi.org/10.1016/j.renene.2020.06.134

Sinha A, Shahbaz M (2018) Estimation of Environmental Kuznets Curve for $\mathrm{CO}_{2}$ emission: Role of renewable energy generation in India. Renew Energy 119:703-711. https://doi.org/10.1016/j.renene.2017.12.058

Sun W, Huang CC (2020) How does urbanization affect carbon emission efficiency? Evidence from China. J Clean Prod 272:122828. https://doi.org/10.1016/j.jclepro.2 020.122828

Su Y, Yu YQ (2020) Spatial agglomeration of new energy industries on the performance of regional pollution control through spatial econometric analysis. Sci Total Environ 704:135261. https://doi.org/10.1016/j.scitotenv.2019.135261

Sugiawan Y, Kurniawan R, Managi S (2019) Are carbon dioxide emission reductions compatible with sustainable well-being? Appl Energy 242:1-11. https://doi.org/10.10 16/j.apenergy.2019.03.113

Tobler WR (1970) A Computer Movie Simulating Urban Growth in the Detroit Region. Econ Geogr 46:234-240. https://doi.org/10.2307/143141

Vettorato D, Geneletti D, Zambelli P (2011) Spatial comparison of renewable energy supply and energy demand for low-carbon settlements. Cities 28(6):557-566. https://doi.org/10.1 016/j.cities.2011.07.004

Vrontisi Z, Charalampidis I, Paroussos L (2020) What are the impacts of climate policieson trade? A quantified assessment of the Paris Agreement for the G20 economies. Energy Pol 139:111376. https://doi.org/10.1016/j.enpol.2020.111376

Withey P, Johnston C, Guo JG (2019) Quantifying the global warming potential of carbon dioxide emissions from bioenergy with carbon capture and storage. Renew Sustain Energy Rev 115:109408. https://doi.org/10.1016/j.rser.2019.109408

Wu T, Yang SW, Tan JJ (2020) Impacts of government R\&D subsidies on venture capital and renewable energy investment—an empirical study in China. Res Pol 68:101715. https://doi.org/10.1016/j.resourpol.2020.101715

Yang XL, He LY, Zhong ZQ, Wang D.Q (2020) How does China's green institutional environment affect renewable energy investments? The nonlinear perspective. Sci Total 
Environ 727:138689. https://doi.org/10.1016/j.scitotenv.2020.138689

Yang XY, Jiang P, Pan Y (2020) Does China's carbon emission trading policy have an employment double dividend and a Porter effect? Energy Pol 142:111492. https://doi.org/10.1016/j.enpol.2020.111492

Yao SJ, Zhang S, Zhang XM (2019) Renewable energy, carbon emission and economic growth: A revised environmental Kuznets Curve perspective. J Clean Prod 235:1338-1352. https://doi.org/10.1016/j.jclepro.2019.07.069

You KF, Solomon OH (2015) China's outward foreign direct investment and domestic investment: An industrial level analysis. China Econ Rev 34:249-260. https://doi.org/10.1016/j.chieco.2015.02.006

Yu SW, Zheng YL, Li LX (20190 A comprehensive evaluation of the development and utilization of China's regional renewable energy. Energy Pol 127:73-86. https://doi.or g/10.1016/j.enpol.2018.11.056

Zhang J, Wu GY, Zhang JP (2004) The Estimation of China's provincial capital stock: 1952-2000. Econ Res J 10:35-44. https://kns.cnki.net/kcms/detail/detail.aspx?dbcod $\mathrm{e}=\mathrm{CJFD} \& \mathrm{dbname}=\mathrm{CJFD} 2004 \&$ filename $=\mathrm{JJY} J 200410004 \& \mathrm{~V}=\mathrm{f} 8 \mathrm{c} 3 \mathrm{dhGN04} \% 25 \mathrm{mmd} 2 \mathrm{~F}$ REI3VIjzuOEIer8fMdjTNPq340fZQSg\%25mmd2BZQZA8o7L0Ukp\%25mmd2FJ\%25 mmd2Fq6LbAV (In Chinese)

Zhang X, Geng Y, Shao S, Wilson J, Song XQ, You W (2020) China's non-fossil energy development and its $2030 \mathrm{CO}_{2}$ reduction targets: The role of urbanization. Appl Energy 261:114353. https://doi.org/10.1016/j.apenergy.2019.114353

Zhao X, Luo DK (2017) Driving force of rising renewable energy in China: Environment, regulation and employment. Renew Sustain Energy Rev 68(1):48-56. https:// doi.org/10.1016/j.rser.2016.09.126 